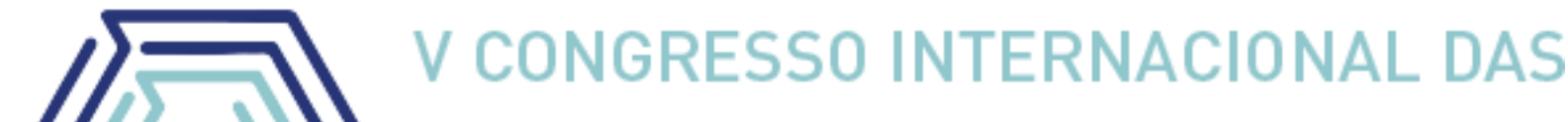 LICENCIATURAS COINTER - PDVL 2018
}

\section{IMERSÃO SENSORIAL: A IMPORTÂNCIA DA DISCUSSÃO SOBRE DIFICULDADES VIVIDAS PELAS PESSOAS COM DEFICIÊNCIA}

\section{SENSORY IMMERSION: THE IMPORTANCE OF DISCUSSION ON DIFFICULTIES LIVED BY DISABLED PEOPLE}

\author{
Apresentação: Pôster
}

Wendell Kennedy Azevedo Vasconcelos ${ }^{1}$; Maicon Gonçalves Balbino ${ }^{2}$; Alisson Abreu Rodrigues $^{3}$; Lucas Carvalho dos Santos e Silva ${ }^{4}$; Adriana Ferreira De Sousa ${ }^{5}$

\section{DOI: https://doi.org/10.31692/2358-9728.VCOINTERPDVL.2018.00213}

\section{Introdução}

De acordo com a Convenção Internacional sobre os Direitos das Pessoas com Deficiência instituída pelo decreto $\mathrm{n}^{\circ}$ 6.949, de 25 de agosto de 2009, conceitua as pessoas com deficiência como aquelas que têm impedimentos de longo prazo de natureza física, mental, intelectual ou sensorial, os quais, em interação com diversas barreiras, podem obstruir sua participação plena e efetiva na sociedade em igualdades de condições com as demais pessoas. Segundo estimativas, 24,6 milhões de pessoas, ou $14,5 \%$ da população total, apresentam algum tipo de deficiência, como dificuldade de enxergar, ouvir, locomover-se ou, ainda, deficiência física ou mental.

Do ponto de vista educacional, os desafios em relação à inclusão são variados, pois as instituições de ensino, da educação básica à superior, terão de lidar com a eliminação de várias barreiras, desde as de caráter arquitetônico até as encontradas na comunicação e nas atitudes (BERSCH, 2013). Por isso a inclusão escolar propõe e gerencia a eliminação de barreiras arquitetônicas, instrumentais, comunicacionais e atitudinais, tanto na sala de aula quanto nos demais espaços da escola buscando sempre recursos e estratégias que promovam

\footnotetext{
${ }^{1}$ Graduando de Biologia do Instituto Federal de Educação, Ciência e Tecnologia do Piauí, delkrock@hotmail.com

${ }^{2}$ Graduando de Biologia do Instituto Federal de Educação, Ciência e Tecnologia do Piauí, , maicongoncalves925@gmail.com

${ }^{3}$ Graduando de Biologia do Instituto Federal de Educação, Ciência e Tecnologia do Piauí, abreu.alisson96@gmail.com

${ }^{4}$ Graduando de Biologia do Instituto Federal de Educação, Ciência e Tecnologia do Piauí, lucascarvalhoesilva@gmail.com

${ }^{5}$ Graduando de Biologia do Instituto Federal de Educação, Ciência e Tecnologia do Piauí, , adrianafs27@gmail.com
} 
acesso e permanência dos alunos e colaboradores com deficiência em todo contexto educacional e laboral.

A proposta aqui apresentada, objetivou a imersão dos voluntários nas dificuldades vividas pelas pessoas com deficiência, coletando as percepções apresentada durante a execução e término das atividades, na tentativa de evidenciar como as dificuldades passadas pelos alunos com deficiências podem influenciar diversos aspectos da sua vida.

Tentamos a partir da experiência fazer com que as pessoas percebessem que a deficiência pode limitar em muitos aspectos, principalmente no contexto educacional, onde o sucesso ou o insucesso do aluno pode ser promovido com a acessibilidade ou não dos espaços.

\section{Fundamentação Teórica}

Atualmente, a prática da inclusão social é discutida em âmbito nacional e parte do princípio de que, para inserir todas as pessoas, a sociedade deve ser capaz de atender às demandas de todos seus membros (MAZZOTTA \& D'ANTINO, 2011). Neste sentido, também não é admissível qualquer tipo de preconceito, discriminação, barreira social, cultural e pessoal.

Segundo Rebelo e Kassar (2018), na contemporaneidade, quando as atenções se voltam à organização de uma educação inclusiva, a questão da acessibilidade ganha força, embora tenhamos constatado as inúmeras fragilidades presentes no cotidiano escolar . No que se refere à acessibilidade, observamos que já houve avanços significativos, em âmbito nacional, sobretudo no aspecto pertinente à legislação, às políticas públicas, aos movimentos sociais, que repercutem na desconstrução de práticas segregacionistas, aumentando o contingente desses alunos com deficiência nas escolas.

Certamente, reconhecemos que o espaço escolar não está devidamente preparado para o atendimento a esses alunos, assim como também temos clareza da complexidade desse processo no qual visa a inclusão do aluno deficiente no âmbito escolar. Entretanto, acreditamos que é a pressão, advinda da suas presenças, na escola, quebrará a invisibilidade dessa representativa parcela da população brasileira (LIMA, 2015).

Assim, estaremos mesmo a passos mais lentos do que o desejado, removendo as barreiras para a aprendizagem e, consequentemente, possibilitando às pessoas com deficiência a acessibilidade ao mundo do trabalho e social. Corroboramos com o pensamento de 
Bianchetti e Freire, (2004, p. 66) de que "não é a distinção física ou sensorial que determina a humanização ou desumanização do homem. Suas limitações ou ilimitações são determinadas social e historicamente".

A escola deve buscar cada vez mais se preparar e incluir com mais qualidade pois precisa promover a sua atividade fim que é a educação de todos, sejam pessoas com ou sem deficiências.

\section{Metodologia}

Esta pesquisa tem caráter qualitativo e cunho experimental, elaborada através de uma atividade proposta onde pode-se colocar os 54 voluntários que participaram da Semana da Química e Biologia do Instituto Federal do Piauí 2018 em contato com as dificuldades vividas pelas pessoas com deficiência.

Primeiramente houve a preparação da sala de aula isolando-a da entrada de luz pelas janelas e portas, dispondo as cadeiras e as caixas de papelão de forma a constituir o percurso no qual o voluntário realizou o trajeto, fez-se o uso de uma estante dispondo os livros na sua parte mais alta e por fim distribuindo os objetos na mesa, posteriormente deu-se início as atividades levando o voluntário a realizar as atividades..

Sendo elas locomover-se com a cadeira de rodas no percurso com obstáculos, tentar pegar um livro na parte mais alta da estante sem se levantar da cadeira de rodas, em seguida já com a sala escura e com a venda o voluntário refazer o percurso com os obstáculos, onde ao final teve que tentar descobrir quais objetos estão dispostos na mesa, utilizando o tato e o olfato.

Ligou-se a luz, onde posteriormente o voluntário fez o uso de um abafador auricular do tipo concha, e foi solicitado a ele por meio de gestos, qual livro ele deveria pegar novamente na estante, ao fim sendo explanado ao voluntariado de forma rápida e sucinta os objetivos da prática e a importância dos sentidos, verificando oralmente e por meio de resposta a questionários as suas considerações após vivenciar tais dificuldades.

Figura 1: Disposição da Sala e percurso e lista de materiais e quantidade Fonte: própria 


\begin{tabular}{|l|c|c|c|c|}
\hline & Material Especificado & Quantidade & Material Especificado & Quantidade \\
\hline Venda & 1 & Estantes \\
\hline \\
\hline
\end{tabular}

\section{Resultados e Discussões}

Com a análise dos dados e dos discursos dos participantes da atividade, ficou perceptível que a prática forneceu de forma eficiente uma modificação nas perspectivas dos voluntários sobre as dificuldades vividas pelas pessoas com deficiência, onde boa parte chegaram a conclusão que a prática fez com que refletissem sobre tais dificuldades de uma forma profunda.

Gráfico 1 : A prática da oficina de imersão fez com que você refletisse acerca das dificuldades de uma pessoa deficiente.

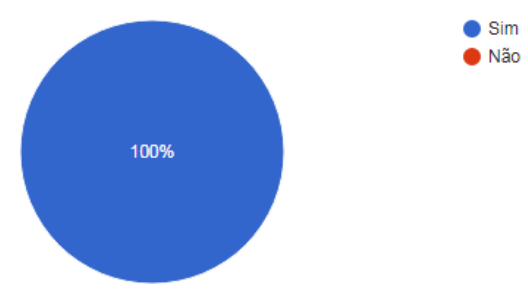

Gráfico 2 : Práticas Relacionadas a inclusão de pessoas com deficiências bons resultados para a educação.

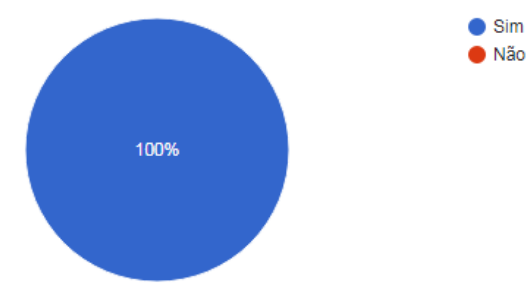

Questionando os voluntários sobre a convivência com as dificuldades, mais da metade já deixaram de ajudar uma pessoa com deficiência física por não saber lidar com tal situação, onde em seus discursos geralmente apresentam o argumento de que não sabem como conduzir, tratar ou chegar a oferecer ajuda a uma pessoa com deficiência, percebeu-se também que a maior parte dos participantes já presenciou alguma pessoa com deficiência passar por alguma dificuldade, onde segundo Montilha (2009), às percepções do público em geral em relação às dificuldades das pessoas com deficiências não contemplam de forma eficiente a levar uma melhor interação, assim corroborando para uma certa displicência acerca das dificuldades vividas.

Gráfico 3 : Você já deixou de ajudar alguma pessoa com com com deficiência por não saber lidar com tal situação? dificuldade
Gráfico 4 : Você já presenciou alguma pessoa deficiência passar por algum tipo de 

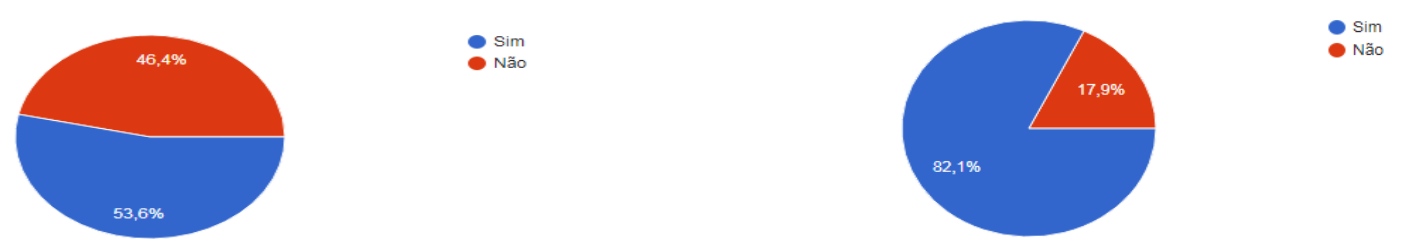

No discurso e nos dados obtidos em relação a políticas públicas que possam vir a auxiliar na tentativa de melhorar a vida das pessoas com deficiência, podemos perceber que mais da metade dos participantes da atividade entendem que as políticas pública não são eficientes em melhorar a vida das pessoas com deficiência, onde para Figueiredo (2015) uma política educacional aparentemente bem estruturada, constata-se a ineficiência na execução dessa política no que se refere a sua missão precípua no processo ensino-aprendizagem.

Gráfico 5: Políticas públicas trabalham de forma a melhorar a vida das pessoas com deficientes.

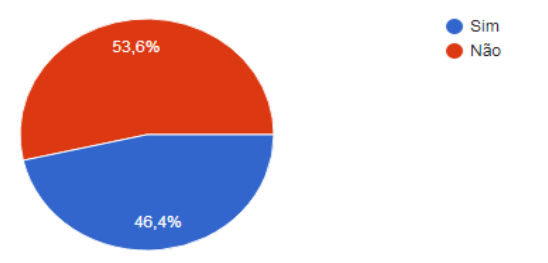

\section{Conclusões}

Acerca da análise dos dados e dos discursos obtidos conclui-se que há uma necessidade instantânea de uma melhor discussão dentro do âmbito acadêmico e escolar sobre as dificuldades vividas pelas pessoas com deficiências, pois muitos dos participantes em diversas oportunidades deixam de ajudá-los por não possuir o conhecimento para tal situação, assim verificando que o processo que pode contribuir para uma melhora significativa na vida dos alunos com deficiência não parte somente das políticas públicas, mas também do bom convívio com o real dimensionamento por parte dos chamados socialmente de "normais" das dificuldades que o nosso mundo impõe às pessoas com deficiências físicas.

Ter vivenciado esta prática foi importante para a formação como cidadão e professor, onde passou-se a enxergar e promover a discussão acerca das dificuldades das pessoas com deficiência, onde houve o incentivo a buscar novas informações e formações, para que na futura vida profissional sempre nos dedicar em garantir que as pessoas com deficiência tenham o direito de ter acesso ao conhecimento da melhor forma possível.

\section{Referências}


BIANCHETTI, L.; FREIRE, I. M. (Org.). Um olhar sobre a diferença: interação, trabalho e cidadania. 6. ed. São Paulo: Papirus, 2004.

FIGUEIREDO, R. M. É.; KATO, O. M.. Estudos Nacionais Sobre O Ensino Para Cegos: Uma Revisão Bibliográfica. Rev. bras. educ. espec., Marília , v. 21, n. 4, p. 477-488, Dec. 2015. Disponível em <http://www.scielo.br/pdf/rbee/v21n4/1413-6538-rbee-21-04-00477.pdf>. acessado em: 29 de junho de 2018

MAZZOTTA, M. J. S. and D'ANTINO, M. E. F. Inclusão social de pessoas com deficiências e necessidades especiais: cultura, educação e lazer. Saude soc. [online]. 2011, vol.20, n.2, pp.377-389. ISSN 0104-1290. Disponível em: 〈http://dx.doi.org/10.1590/S0104-12902011000200010〉 acessado em: 29 de junho de 2018

MONTILHA, R. C. I. et al. Percepções de escolares com deficiência visual em relação ao seu processo de escolarização. Paidéia (Ribeirão Preto), Ribeirão Preto, v. 19, n. 44, p. 333-339. 2009. disponível em <http://www.scielo.br/pdf/paideia/v19n44/a06v19n44.pdf>. acessado em 30 de junho de 2018.

REBELO, A. S.; KASSAR, M. C. M. Escolarização dos alunos da educação especial na política de educação inclusiva no Brasil. XII Encuentro Iberoamericano de Educación 2017 . Brasília, DF, v.11 n.1, p.56-66. Disponível em <http://revista.ibict.br/inclusao/article/view/4079/3591> acessado em: 29 de junho de 2018.

LIMA, T. B. Educação Inclusiva: Verdades E Utopias No Ensino Fundamental. In: I Encontro Nordestino De Inclusão No Ensino Superior, 1., 2015. Alagoas. Anais... Universidade Federal de Alagoas. Disponível em: <http://www.seer.ufal.br/index.php/eaei/article/view/2131/1612> acessado em: 30 de junho de 2018.

BERSCH, R. C. R.; Martins, D. S. . Serviço de Tecnologia Assistiva em Escolas Públicas e Processos de Avaliação para Acessibilidade ao Computador e à CAA. In: Liliana Maria Passerino, Maria Rosangela Bez, Ana Cristina Cipriano Pereira, Adriana Peres. (Org.). Comunicar para Incluir. 1ed.Porto Alegre: CRBF, 2013, v. 1, p. 439-463. Disponível em: $<$ http://www.assistiva.com.br/Recursos_Ped_Acessiveis_Avaliacao_ABR2013.pdf> acessado em: 30 de junho de 2018

BRASIL. Decreto n. 6.949, de 25 de agosto de 2009a. Disponível em:<<http://www.planalto.gov.br/ccivil_03/_ato2007-2010/2009/decreto/d6949.html> acessado em: 23 junho de 2013 